\title{
DRUGAČIJI PRISTUP PREVENCIJE I LIJEČENJA BOLNIH LEĐA NA RADNOM MJESTU
}

UDK 616.711-002-084

PRIMLJENO: 30.10 .2015

PRIHVAĆENO: 4.4 .2016

\begin{abstract}
SAŽETAK: Bolna leđa su jedan od najčěšćih uzroka izostanka s posla u Hrvatskoj i svijetu. Samo je prošle godine 32.000 radnika bilo onesposobljeno zbog boli u ledima. Posljedica toga su veliki troškovi koji se odnose na radnika, poslodavca, zdravstveni i mirovinski sustav. Stoga je potrebno preventivno djelovati kako bi se smanjila učestalost i trajanje ove bolesti, a preventivne aktivnosti treba provoditi na radnom mjestu, jer uvjeti radnog mjesta mogu izravno izazvati pojavu boli u leđima, is druge strane, mogu neizravno pogoršati već postojeće stanje nastalo nevezano uz radno mjesto. U prevenciji i liječenju boli u leđima dominantnu ulogu ima biomedicinski model. Prema njemu nastanak bolesti je isključivo i samo posljedica organskog poremećaja. Tijekom niza godina takav se model nije pokazao učinkovitim kod kroničnih bolesti kao što su bolna leđa, već samo kod akutnih bolesti. Kronične bolesti su multifaktorijalne, te se kao primjereniji pristup pokazao biopsihosocijalni model. Prema tom modelu, bol u leđima nastaje kao posljedica fizioloških, psihičkih i socijalnih faktora koji su u međusobnoj interakciji, a jačina simptoma i razina onesposobljenosti ovise o toj interakciji. Drugim riječima, psihički i socijalni faktori posreduju u nečijoj reakciji na organski poremećaj tako, ako izlječenje organskog poremećaja nije moguće, uspješnim ishodom smatra se povratak normalnim aktivnostima na poslu i u svakodnevnom životu. U sklopu biopsihosocijalnog modela uspješnim preventivnim mjerama pokazale su se: edukacija koja obuhvaća sva tri aspekta boli (biomedicinski, psihološki i sociološki), fizička aktivnost prilagođena pojedincu i prilagodba radnog mjesta trenutnim zdravstvenim mogućnostima radnika.
\end{abstract}

Ključne riječi: bol u leđima, biopsihosocijalni model, preventivne mjere na radnom mjestu

\section{UVOD}

Bol u leđima može se nazvati epidemijom suvremenog doba i čini jedan od vodećih zdravstvenih problema. Pripada skupini koštano-mišićnih bolesti koje su definirane kao bolesti koje zahvaćaju mišiće, tetive, ligamente, zglobove, periferne žile i živce (Punnett, Wegman, 2004.). U Velikoj Britaniji smatra se najučestalijim razlogom izostanka s posla u osoba mlađih od 40

*Marina Mihalinac Bolanča, dr. med. (mmihalinac@hzzzsr.hr), dr. sc. Marija Bubaš, Dijana Krišto, dr. med., Hrvatski zavod za zaštitu zdravlja i sigurnost na radu, Cimermanova 64a, 10000 Zagreb, Hrvatska godina, a u Hrvatskoj je prema podacima kampanje "Fit for Work" u 2014. godini 32.000 ljudi bilo onesposobljeno zbog boli u leđima. Može se pojaviti u bilo kojoj životnoj dobi, pri čemu pojavnost raste s povećanjem dobi (Summers, Jinnett, Bevan, 2015.). Uzroci nastanka su mnogobrojni, a na neke od njih može se preventivno djelovati (npr. stil života i radni uvjeti). Uvjeti radnog mjesta mogu izravno izazvati pojavu boli u leđima, ali s druge strane mogu neizravno pogoršati već postojeće stanje nastalo nevezano uz radno mjesto. Najrizičnija su radna mjesta na kojima radnik većinu radnog vremena prenosi teški teret, položaj tijela nije neutralan, izložen je vibracijama i stresu (Summers, Jinnett, Bevan, 
2015.). S obzirom na kompleksnost uzroka boli u leđima, teško je djelovati na sprečavanje pojave prve epizode boli u leđima. Preventivne aktivnosti moraju biti osmišljene na način koji će dovesti do smanjenja ponovne pojave bolnih epizoda, apsentizma, čestih bolovanja, neracionalnog korištenja zdravstvene usluge, prijevremene pojave invalidnosti i nesposobnosti za rad.

Bol u leđima je uzrok brojnih troškova i problema. Za radnika: izostanak s posla, te manja primanja. Za poslodavca: dodatni troškovi zbog bolovanja, problem manjka radnika, preopterećivanje ostalih radnika, smanjenje produktivnosti, produljenje rokova za dogovorene poslove i na kraju manji profit tvrtke. Za zdravstveni sustav: troškovi vezani uz dugotrajno liječenje i rehabilitaciju.

Hrvatski zavod za zdravstveno osiguranje izrađuje godišnje izvješće o danima provedenim na bolovanju za pojedinu skupinu bolesti (HZZO, 2014.). U razdoblju od siječnja do kolovoza 2013. godine bilo je ukupno 4.636 slučajeva bolesti intervertebralnih diskova i ostalih dorzopatija (M50-M54 prema Međunarodnoj klasifikaciji bolesti) s prosječnim brojem dana bolovanja 95,92 dana po slučaju. Za navedene bolesti to je iznosilo ukupno 444.689 dana bolovanja, dok je za usporedbu za isto razdoblje broj slučajeva zloćudnih novotvorina dojke (C50) iznosio 417 s ukupnim brojem dana bolovanja od 87.591. Navedeni podaci ukazuju da ukupni broj dana bolovanja zbog boli u leđima višestruko prelazi ukupni broj dana bolovanja zbog nekih težih bolesti poput zloćudne bolesti dojke.

\section{BIOPSIHOSOCIJALNI PRISTUP}

U prevenciji i liječenju boli u leđima dominantnu ulogu ima biomedicinski model. Prema tom modelu bolest nastaje kao posljedica organskog poremećaja, a povezanost tijela i uma je zanemarena, te smatra da su simptomi i razina onesposobljenosti pacijenta izravno proporcionalni organskom poremećaju. Jer, povećanje organskog poremećaja će uzrokovati pojavu jačih simptoma i veću razinu tjelesne onesposobljenosti i obrnuto, smanjenje organskog poremećaja će umanjiti simptome i tjelesnu onesposobljenost. U slučaju bolnih leđa to bi značilo da su jačina boli i poteškoće pri savijanju kralježnice proporcionalni veličini organskog poremećaja. No, u praksi smo često svjedoci da to ne mora biti slučaj, te da kod dokazanog malog organskog poremećaja pacijent može osjećati jake bolove i imati značajno fizičko ograničenje. U skladu s navedenim prevencija i liječenje usmjereni su na organski poremećaj uz zanemarivanje psihičke komponente bolesti, te se uspješnost liječenja promatra isključivo kao smanjenje organskog poremećaja. U takvim slučajevima može doći do potpunog zanemarivanja spomenute psihičke i socijalne komponente samog radnika koja uvelike utječe na njegovu sposobnost povratka na posao te obavljanje ostalih svakodnevnih obveza.

Tijekom niza godina takav model nije se pokazao učinkovitim kod kroničnih bolesti kao što su bolna leđa, već samo kod akutnih bolesti. Kronične bolesti su multifaktorijalne i ovakav pristup ne polučuje zadovoljavajuće rezultate pri povratku radnika na posao i u svakodnevne obveze. Kao primjereniji pristup u prevenciji i

Tablica 1. Podaci o bolovanju prema MKB klasifikaciji za razdoblje I.-VIII. 2013.

Table 1. Data on the incidence of sick leaves according to the MKB classification for period January-August 2013

\begin{tabular}{||l|c|c|c|c||}
\hline \hline MKB dijagnoza & $\begin{array}{c}\text { MKB } \\
\text { šifra }\end{array}$ & $\begin{array}{c}\text { Broj } \\
\text { slučajeva }\end{array}$ & $\begin{array}{c}\text { Broj } \\
\text { dana bolovanja }\end{array}$ & $\begin{array}{c}\text { Dani po } \\
\text { slučaju }\end{array}$ \\
\hline Bolesti intervertebralnih diskova i ostalih dorzopatija & M50-M54 & 4.636 & 444.689 & 95,92 \\
\hline Zloćudna novotvorina dojke & C50 & 417 & 87.591 & 210,05 \\
\hline Dijabetes melitus & E10-E14 & 214 & 27.244 & 127,31 \\
\hline Akutni infarkt miokarda & I21-I23 & 400 & 61,666 & 154,17 \\
\hline Cerebrovaskularni inzult & I60-I64 & 243 & 67,998 & 279,83 \\
\hline
\end{tabular}

MKB: Međunarodna klasifikacija bolesti i srodnih stanja

Izvor: Hrvatski zavod za zdravstveno osiguranje 
liječenju kroničnih bolesti pokazao se biopsihosocijalni model (Havelka, 2015.).

Taj model koristi se cjelovitim pristupom za uspješno razumijevanje, prevenciju i liječenje bolesti. Problem bolnih leđa vidi kao posljedicu kombinacije fizioloških, psihičkih i socijalnih faktora (Summers et al., 2015.) koji su u međusobnoj interakciji, nadograđuju se, a jačina simptoma i razina onesposobljenosti ovise o toj interakciji. Drugim riječima, psihički i socijalni faktori posreduju u nečijoj reakciji na organski poremećaj. U ovom modelu radnik je aktivni sudionik, te snosi odgovornost za uspjeh u procesu prevencije i liječenja. U slučajevima kada izlječenje organskog poremećaja nije moguće, uspješnim ishodom se smatra povratak normalnim aktivnostima na poslu i u svakodnevnom životu.

Model je kritiziran zbog pretjeranog isticanja psihološke komponente i zanemarivanja socijalne. Novijim istraživanjima je utvrđeno da model evoluira (Schultz et al., 2007.), te se sada više pozornosti posvećuje socijalnim faktorima.

Ovdje će se prikazati najčešće mjere koje služe za prevenciju bolnih leđa. Sve one su dio biopsihosocijalnog modela.

\section{EDUKACIJA}

Prvi korak u prevenciji bilo koje bolesti jest podizanje svijesti o značaju prevencije te edukacija koja uključuje radnika, stručnjaka zaštite na radu, stručnjaka u ljudskim resursima (ako postoje unutar tvrtke) te viši i visoki menadžment o važnosti provođenja prevencije te načinima na koji je treba provesti. Edukacija u području prevencije bolesti sustava za kretanje treba biti sveobuhvatna, te uključivati definiranje rizičnih faktora za razvoj bolesti kao i koristi koje motiviraju radnika i poslodavca za uključivanjem u njezinu provedbu. Istraživanja su pokazala da je najučinkovitija ona edukacija koja obuhvaća biomedicinski, psihološki i sociološki aspekt boli (Waddell, Burton, 2001.). Biomedicinski aspekt podrazumijeva edukaciju o anatomiji, biomehanici kralježnice, pravilnoj posturi tijela, tehnikama pravilnog dizanja tereta i ergonomiji.
Psihološki aspekt fokusiran je na edukaciju oboljelog radnika o tome kako se na pravilan način nositi s bolešću. Dio edukacije obuhvaća učenje tehnika relaksacije koje radniku omogućavaju lakše nošenje sa svakodnevnim stresom te doživljavanjem boli i onesposobljenosti i osvješćivanje radnika koja su fizička ograničenja pojedinca realna, a koja su uzrokovana strahom. Nadalje, radnika je potrebno motivirati za aktivno uključivanje u svoje liječenje i preuzimanje odgovornosti za svoje zdravlje te neprestano poticati njegovu fizičku aktivnost unatoč strahu od boli.

Sociološki aspekt usmjeren je na senzibilizaciju i edukaciju obitelji i okoline oboljele osobe. Potrebno ih je podučiti kako pravilno doživljavati bolest njihova člana i koja su njegova realna ograničenja, te kako stvoriti pozitivno okružje koje će poticati oboljelu osobu na aktivno i odgovorno sudjelovanje u liječenju. Naime, mnoge obveze koje je do tada izvršavala bolesna osoba od sada će morati preuzeti članovi obitelji kao i kolege na poslu, što za njih predstavlja dodatno opterećenje, a dugoročno djeluje destimulativno na bolesnika. Poticajno okružje pridonijet će skorijem vraćanju normalnim životnim aktivnostima i zadacima te ujedno pridonijeti bržem ozdravljenju.

\section{FIZIČKA AKTIVNOST}

U općoj populaciji postoji pogrešno uvjerenje o izbjegavanju bilo kakve fizičke aktivnosti pri pojavi boli u leđima. Naime, kada se pojavi bol u leđima, mirovanje i izbjegavanje fizičke aktivnosti postaje glavni obrazac ponašanja, što dovodi do negativnih učinaka. Trajanje boli je češće i dulje, a povratak na posao i aktivnostima svakodnevnog života su otežani i zahtijevaju dulju vremensku prilagodbu. Medicinski stručnjaci koji se bave ovom problematikom preporučuju upravo fizičku aktivnost kao učinkovito terapijsko sredstvo za smanjenje boli i poboljšanje funkcije bolnih leđa. Istraživanja potvrđuju da je fizička aktivnost učinkovita preventivna mjera za sprečavanje ponovnog javljanja boli u leđima, i sredstvo za ublažavanje postojećih bolova s krajnjim ciljem - smanjenjem trajanja bolovanja (Balagué et al., 2004.). Budući da su uzroci 
križobolje različiti, nije moguće preporučiti jedinstveni oblik vježbanja za sve, jer ne postoje dokazi koji potvrđuju da je jedan tip vježbanja bolji od drugog (Balagué et al., 2004., Grazio, 2013.).

Stoga je svaka vrsta vježbi poželjna, na radnom mjestu u obliku svakodnevnog istezanja, zagrijavanja mišića prije početka fizičkog rada, a u slobodno vrijeme u obliku redovitog vježbanja, hodanja, plivanja, tj. aktivnog načina živIjenja.

\section{PRILAGODBA RADNOG MJESTA}

Važnu ulogu u prevenciji bolnih leđa i bržoj rehabilitaciji oboljelog radnika zasigurno ima prilagodba radnog mjesta radniku. Fizički zahtjevi posla ne smiju nadilaziti tjelesni kapacitet radnika, te se trebaju mijenjati u skladu s povećanjem ili smanjenjem tjelesnog kapaciteta. Istraživanja pokazuju što je dulje radnik na bolovanju, manja je vjerojatnost povratka na posao. Upravo zato, potrebno je što ranije omogućiti povratak radnika u njegovu radnu okolinu uz provedene prilagodbe radnog mjesta, redefiniranjem težine i trajanja posla kako zahtjevi posla ne bi nadilazili fizički kapacitet bolesnog radnika. Posao treba biti dizajniran na način da ne pogoršava simptome, već pomaže rehabilitaciju bolesnog radnika (Stock et al., 2005.). Prema Gatchelu kombinacija nekoliko čimbenika radnog mjesta poput: radne okoline s visokim zahtjevima i/ili malom mogućnošću kontrole, percepcije radnika da stil rukovođenja nije odgovarajući, uvjerenja radnika da radi pod vremenskim pritiskom i slabe potpore kolega, dovodi do sporijeg oporavka. Neki od primjera prilagodbe radnog mjesta su: prilagođavanje stola i stolica karakteristikama radnika i zahtjevima posla, nadalje mogućnost uporabe pomagala koja olakšavaju rad ili omogućuju odgovarajući položaj tijela pri prenošenju tereta, te uporaba alata koji ne vibriraju, kraće radno vrijeme za vrijeme trajanja rehabilitacije, izmjena sjedećeg i stajaćeg radnog mjesta te oslobađanje od poslova koji mogu pogoršati simptome. Prema Europskim smjernicama za prevenciju boli u donjem dijelu leđa, provođenje samo ergonomskih mjera uz istodobno neuvažavanje i organi- zacijskih mjera ne daje zadovoljavajući učinak. Ergonomske mjere su učinkovite samo kada se primjenjuju zajedno s organizacijskim mjerama i obrnuto (Balagué et al., 2004.).

\section{ZAKLJUČAK}

$U$ današnje vrijeme najzastupljeniji model prevencije i liječenja bolesti je biomedicinski, no on se pokazao nedostatnim u slučaju kroničnih bolesti. Bolje rezultate, odnosno kraće trajanje bolovanja i raniji povratak na posao zabilježen je kod primjene biopsihosocijalnog modela. Prema tom modelu problem bolnih leđa je posljedica fizioloških, psihičkih i socijalnih čimbenika o čijoj interakciji će ovisiti jačina simptoma i veličina tjelesne onesposobljenosti. Oboljela osoba ima aktivnu ulogu u svojem liječenju jer snosi odgovornost za uspjeh u procesu prevencije i liječenja. Uspješnim ishodom liječenja smatra se povratak normalnim aktivnostima na poslu te u svakodnevnom životu. U sklopu biopsihosocijalnog pristupa mjere koje su se pokazale učinkovitima jesu: edukacija, fizička aktivnost i prilagodba radnog mjesta. U edukaciju trebaju biti uključeni radnici kao i svi oni koji imaju moć odlučivanja kada u pitanje dođu preventivni programi i njihova provedba. Program treba biti cjelovit te educirati sudionike o biomedicinskim, psihološkim i socijalnim aspektima boli. Kod prevencije i liječenja boli u leđima fizičku aktivnost potrebno je prilagoditi pojedincu, te je treba prakticirati redovito, $i$ to na radnom mjestu i u slobodno vrijeme. Radno mjesto mora biti prilagođeno na način da fizički zahtjevi posla ne nadilaze tjelesni kapacitet radnika. Istraživanja ukazuju na obrnuto proporcionalan odnos između duljine trajanja privremene nesposobnosti za rad i vjerojatnosti radnikovog povratka na posao. Kvalitetna intervencija, stoga, mora ići u pravcu prilagodbe radnog mjesta, težine i trajanja posla s ciljem postizanja zadovoljavajućeg učinka i povratka oboljelog radnika u čim kraćem vremenu na radno mjesto. $\mathrm{Na}$ kraju, uz kombiniranu i usklađenu primjenu svih navedenih mjera moći će se s još više detalja raspravljati o njihovoj učinkovitosti, određivati potrebno vrijeme trajanja pojedine komponente intervencije i radnicima s bolnim leđima omogućiti dulji, sigurniji i kvalitetniji radni vijek. 


\section{LITERATURA}

Balagué, F., Burton A. K., Cardon, G., Eriksen, H.R., Hänninen, O., Harvey, E.L., Henrotin, Y., Lahad, A., Leclerc, A., Müller, G., van der Beek, A.J.: European guidelines for prevention in low back pain, 2004., Dostupno na: http:// www.backpaineurope.org/web/files/WG3_Guidelines.pdf. Pristupljeno: 8.5.2014.

Back pain. Dostupno na: https://www.clinicalkey.com/topics/rheumatology/back-pain. html, Pristupljeno: 6.6.2014

Dall, TM., Gallo, P., Koenig, L., Gu, Q., and Ruiz, D.: Modeling the indirect economic implications of musculoskeletal disorders and treatment, Cost Effectiveness and Reasurce Allocation, 11, 2013, doi: 10.1186/1478-7547-11-5

Grazio, S.: Opći pristup bolesniku s križoboljom, Simpozij povodom svjetskog dana kralježnice, Medicinske vježbe u križobolji, Zagreb, 2013.

Havelka, M.: Zdravstvena psihologija. Dostupno na: http://161.53.244.3/ mladenh/Knjige/Zdravstvena\%20psihologija\%20-\%20nastavni\%20tekstovi.pdf, Pristupljeno: 23.10.2015.

Hrvatski zavod za zdravstveno osiguranje: Izvješce o bolovanju na teret sredstava Hrvatskog zavoda za zdravstveno osiguranje prema Međunarodnoj klasifikaciji bolesti za razdoblje siječanj - kolovoz 2013. godine, Dostupno na: http://www.hzzo-net.hr//dload//publikacije/ web_stopa2_MKB_082013.pdf. Pristupljeno: 26.5.2014.

Hrvatski zavod za zaštitu zdravlja i sigurnost na radu: Smjernica o uređivanju radnih mjesta na kojima se dugotrajno sjedi. Dostu- pno na: http://www.hzzzsr.hr/doc/news_prilozi/doc_1349958518_1.pdf, Pristupljeno: 22.5.2014.

Mihalinac Bolanča, M., Bubaš, M., Krišto, D.: Mjere na radnom mjestu za sprečavanje bolnih leđa. U: Zbornik radova, V. Međunarodno stručno-znanstveni skup "Zaštita na radu i zaštita zdravlja", Zadar,177-181, 2014.

Punnett, L., Wegman, DH.: Work-related musculoskeletal disorders: the epidemiologic evidence and the debate. J Electromyogr Kinesiol., 14, 2004., 1, 13-23.

Schultz, I.Z., Stowell, A.W., Feuerstein, M., Gatchel ,R.J.: Models of Return to Work for Musculoskeletal Disorders, J Occup Rehabil,17, 2007., 327-352.

Stock, S., Baril, R., Dion-ubert, C., Lapointe, C., Paquette, S., Sauvage, J., Simoneau, S., Vaillancourt, C.: Work-related Musculoskeletal Disorders Guide and Tools for Modified Work, 2005., Dostupno na: http://www.irsst.qc.ca/media/documents/pubirsst/omrt-en.pdf. Pristupljeno: 23.10.2015.

Summers, K., Jinnett, K., Bevan, S.: Musculoskeletal disorders, Workforce Health and Productivity in the United States, 2015., Dostupno na: http://www.fitforworkeurope.eu/White $\% 20$ paper\%20-\%20Musculoskeletal\%20disorders $\% 20$ workforce $\% 20$ health\%20and\%20productivity\%20in\%20the\%20USA\%20final.pdf. Pristupljeno: 23.10.2015.

Waddell, G., Burton, A. K.: Occupational health guidelines for the management of low back pain at work: evidence review, Occup Med Lond, 51, 2001., 124-135. 


\section{AN ALTERNATIVE APPROACH TO THE PREVENTION AND TREATMENT OF SORE BACK AT THE WORK PLACE}

SUMMARY: Sore back is one of the most common causes of absence from work in Croatia and worldwide. Only in the past year 32,000 workers were temporarily disabled due to sore back. The cost of this to the workers, employers, the health care and retirement fund are enormous. Prevention is imperative to reduce the incidence and duration of this health problem. Prevention measures must be put in place at the work place itself, as the work place can be directly responsible for the sore back syndrome but it can also indirectly contribute to the existing condition caused by other factors. The prevention and treatment of sore back still predominantly relies on the biomedical model. In this model, the affliction is attributed exclusively to organic causes. Over the years, this model has proven effective in cases of acute disease but ineffective in chronic disorders such as sore back. Chronic diseases are multifactorial and thus for them the biopychosocial model seems to be a more adequate path for follow. According to this model, sore back is caused by an interaction of physiological, psychological and social factors where the severity of symptoms and the degree of disability are in direct correspondence with this interaction. In short, psychological and social factors affect a patient's reaction to the organic disorder. If complete cure of the organic disorder is not feasible, the return to the usual daily activities and work are considered a successful outcome. The biopsychosocial model includes proven measures such as education addressing all three aspects of the pain (biomedical, psychological and social), physical activity tailored to suit the individual, and adjustments made to the work place to help the health status of the worker.

Key words: sore back, biopsychosocial model, prevention measures at the work place

Professional paper

Received: 2015-10-30

Accepted: 2016-04-04 